\title{
El Derecho a la Información en América Latina
}

Helen Darbishire*

\section{El contexto internacional}

En los últimos años, el derecho de acceso a la información se ha fortalecido notablemente en todo el mundo, incluso en América Latina. Dicho fortalecimiento se expresa en el reconocimiento de este derecho mediante la adopción, en un número creciente de países, de leyes de acceso a la información: de un total de 65 de leyes de este tipo aprobadas en el mundo, 13 son leyes nacionales de acceso a la información en las Américas (véase el Cuadro A al final de este texto) como también decretos en Argentina y Bolivia, y disposiciones de la legislación administrativa en Chile. Estas leyes establecen mecanismos que permiten que el público presente solicitudes de información, fijan plazos de entrega, establecen los fundamentos para excepciones y fijan los límites en cuanto al costo de las copias. Asimismo, hay una serie de leyes subnacionales, como las estaduales en México y las provinciales en Argentina.

La reciente promulgación de leyes de acceso a la información se hace eco de una tendencia global emergente que demuestra que los Estados democráticos deben garantizar la existencia de mecanismos que aseguren el derecho de la gente a tener acceso a la información que está bajo el control del Estado. En las Américas, al igual que en otras partes, estas leyes se complementan con la creciente jurisprudencia basada en disposiciones constitucionales sobre libertad de información y el derecho de presentar peticiones ante las autoridades. La Organización de Estados Americanos, organismo de derechos humanos de la región, reiteró nuevamente mediante la Declaración de la Asamblea General de 2005 (AG/RES. 2121 (XXXV-O/05) que "el acceso a la información pública es requisito indispensable para el funcionamiento mismo de la democracia", e instó a los Estados "que respeten y hagan respetar el acceso a la información pública a todas las personas y promuevan la adopción de disposiciones legislativas o de otro carácter que fueren necesarias para asegurar su reconocimiento y aplicación efectiva para brindar a los ciudadanos amplio acceso a la información pública".

El desarrollo del derecho a la información en las Américas se ha producido tanto en respuesta a las violaciones de los derechos humanos como a problemas de corrupción, y ha sido parte de la oleada regional y global de democratización como de un fenómeno de fines del siglo XX y principios del siglo XXI. En casi todos los casos, la sociedad civil ha desempeñado un papel importante en la promulgación de nuevas leyes de acceso a la información. Un ejemplo de estas campañas es el trabajo

Este comentario está disponible en: www.anuariocdh.uchile.cl 
1 Demanda sometida por la Comisión Interamericana de Derechos Humanos a la Corte Interamericana de Derechos Humanos en el caso de Claude et al. vs. Chile (12.108), 8 de julio de 3005 , párr. 53. realizado por el Grupo Oaxaca en México, que coincidió con el fin de los 70 años de hegemonía del PRI y la asunción del mando del Presidente Vicente Fox, y que, además, aprovechó estas circunstancias para producir una pequeña pero significativa revolución con la aprobación de una de las leyes de acceso a la información de mayor alcance en el mundo. Junto con estos acontecimientos, periodistas, ciudadanos y ONGs de toda la región han hecho un uso dinámico de las disposiciones constitucionales sobre derecho de acceso a la información, habeas data y derecho a presentar peticiones al Estado para lograr algunos triunfos notables en el campo del derecho a la información. En las siguientes secciones, se analizarán más detalladamente estos hechos.

\section{Evolución de la jurisprudencia}

Desde la perspectiva de las leyes de derechos humanos, algunos de los acontecimientos más emocionantes se han producido en el desarrollo de la jurisprudencia nacional e internacional, que establece con creciente firmeza los fundamentos del derecho de acceso a la información en poder del Estado. En julio de 2005, la Comisión Interamericana de Derechos Humanos concluyó, en una petición presentada contra Chile, que el Artículo 13 de la Convención Americana sobre Derechos Humanos incluye el derecho al acceso a información bajo control estatal, al señalar que:

"La importancia de un derecho efectivo al acceso a la información tiene un fundamento sólido en el derecho internacional y comparado de derechos humanos. Aunque no todos los países y organizaciones internacionales fundan el derecho al acceso a la información en poder del Estado en el derecho a la libertad de expresión, existe un consenso creciente en torno a que los gobiernos sí tienen obligaciones positivas de brindar la información en poder del Estado a sus ciudadanos, dado que este derecho es independiente de otros derechos fundamentales"1.

En países tales como Costa Rica, periodistas y ciudadanos han colaborado con una Cámara Constitucional progresista de la Corte Suprema para transformar las disposiciones constitucionales sobre el derecho a presentar peticiones (Artículo 27) y el derecho a información administrativa (Artículo 30) en un sólido cuerpo de jurisprudencia que impone un alto nivel de transparencia al gobierno. La Corte Suprema de Costa Rica señaló en sus fallos que el acceso a la información pública es un "derecho humano inalienable e indispensable" recalcando que "...entes públicos están Ilamados a ser verdaderas casas de cristal en cuyo interior pueden escrutar y fiscalizar, a plena luz del día, todos los administrados. Las administraciones públicas deben crear y propiciar canales permanentes y fluidos de comunicación colectiva en aras de incentivar una mayor participación directa y activa en la gestión pública, y de actuar los principios de evaluación de resultados y rendición de cuentas...". Las decisiones emitidas de acuerdo con esta norma van desde exigir se dé a conocer a los pacientes los fondos disponibles para su tratamiento en un hospital, hasta dar órdenes al Banco Central de divulgar informes del Fondo Monetario Internacional sobre la economía de Costa Rica. 
El reconocimiento del derecho a la información aumenta cada vez más y su posición ya está establecida como un derecho instrumental necesario para el disfrute y protección de otros derechos. Así lo determinó la Corte Europea de Derechos Humanos, que reconoce que se necesita información para hacer cumplir el respeto de la vida familiar y la mantención de un medio ambiente sano y limpio.

El carácter esencial que desempeña la información en la protección de los derechos humanos también ha sido reconocido por las Cortes en las Américas. En Uruguay, por ejemplo, en el caso en que una madre (María del Carmen Almeida de Quinteros) intentaba obtener información acerca de la desaparición de su hija en 1976, la Corte Suprema de Justicia dictaminó en el año 2000 que "es claro que el derecho de información requerido en autos está vinculado a la desaparición de una hija y la actitud del Estado, en negar en forma clara y manifiesta la búsqueda de la información, significa negar el derecho humano y esencial que le asiste a la actora de saber sobre el paradero de su hija".

\section{Análisis de las leyes de acceso a la información}

Si bien la jurisprudencia está contribuyendo en forma importante a definir el ámbito de acción del derecho a la información, en términos generales, solamente mediante leyes de acceso a la información se podrán definir con claridad los mecanismos para su puesta en práctica. Al igual que en el caso de otros derechos que imponen obligaciones positivas al Estado, tales como el derecho a elecciones, o el derecho a la salud y a la educación, se precisa que las leyes hagan efectivos los derechos y asignen los presupuestos correspondientes, además de establecer organismos de fiscalización.

La calidad y el carácter exhaustivo de la ley de acceso a la información son fundamentales para garantizar su cumplimiento uniforme por parte de todos los organismos públicos y actores privados pertinentes. Una de las mejores leyes de la región, y podría decirse del mundo, es la Ley Federal de Transparencia y Acceso a la Información Pública de México (LFTAI), aprobada en junio de 2002. Los elementos esenciales de la ley radican en que todos pueden solicitar información sin tener la obligación de demostrar un interés específico, cumpliendo así con el principio de libertad de información independientemente de las fronteras.

En contraste, la ley de la República Dominicana, aunque bien redactada en general, contiene un pequeño requisito que socava la totalidad de la ley y atenta contra el principio de que toda la información es pública: exige que los solicitantes, al presentar su solicitud, manifiesten la "motivación de las razones por las cuales se requieren los datos e informaciones solicitadas" (Artículo 7.c). Las disposiciones de Canadá tampoco cumplen con la norma mundial, porque limitan el derecho de solicitud de información a ciudadanos canadienses y a residentes del país. En la práctica, esto no tiene sentido, ya que cualquier solicitante puede pedir a otra persona que solicite la información; sin embargo, 
visto en el papel, no deja de ser una clara violación de las normas internacionales de derechos humanos. Como se observa en el Cuadro A, sólo 2 de las 15 jurisdicciones investigadas impusieron límites respecto de quiénes pueden solicitar información.

\section{a) Alcance de las leyes de acceso a la información}

De conformidad con la naturaleza de este derecho, la ley ecuatoriana, que también se ve sólida en el papel, establece claramente que la información pertenece a los ciudadanos, es pública por principio y sólo puede no revelarse en caso de excepciones limitadas. Como sucede típicamente con la mayoría de las leyes de la región, no solamente abarca la administración estatal, sino también a todas las entidades que realizan funciones públicas o que reciben fondos públicos.

A menudo, las controversias sobre la definición adecuada del alcance de las leyes de acceso a la información han impedido su promulgación. En el año 2005, el proyecto de ley de acceso a la información de Argentina fracasó luego de los intentos del Senado por ampliar sus efectos e incluir a una serie de actores no estatales. Se modificó la ley de modo que incluyera a "las entidades privadas, con o sin fines de lucro, que tengan fin público o posean información pública". La sociedad civil y los medios de comunicación temían que se produjera un potencial abuso de esta disposición en el futuro, por ejemplo, al obligar a los periodistas a divulgar fuentes confidenciales de información o requerir que las ONGs respondieran solicitudes de material de investigación sensible relacionado con derechos humanos. Indudablemente, las disposiciones propuestas eran excesivamente amplias comparadas con las normas internacionales actuales: incluso las leyes más progresistas, tales como el South African Promotion of Access to Information Act (2000), efectivamente imponen obligaciones a las entidades privadas de solicitudes de información, pero tan sólo en la medida que dicha información sea aquella "necesaria para el ejercicio o protección de cualquier derecho".

\section{b) Excepciones}

La instauración de excepciones claramente definidas y delimitadas también resulta fundamental para crear un régimen de acceso a la información que defienda el derecho a saber. Como destacó la Comisión Interamericana de Derechos Humanos al determinar que las disposiciones de acceso en Chile no cumplen con la norma internacional:

"Las excepciones previstas en la ley son demasiado amplias y vagas, y confieren un grado excesivo de discrecionalidad al funcionario que determina si se divulga o no la información. (...) En la ley chilena, la tercera excepción, por ejemplo, admite que un tercero referido o "afectado" por la información impida su divulgación, sin demostrar que su interés en mantener la confidencialidad de la información es mayor que el interés público en el acceso a la información. Análogamente, la quinta excepción no equilibra la seguridad nacional o el interés nacional con el interés público en el acceso a la información y no define los términos "seguridad 
nacional" e "interés nacional". Las demás excepciones tienen fallas similares" ${ }^{\prime \prime}$.

c) Información sobre violaciones de los derechos humanos

Independientemente de cómo se definan las excepciones, resulta indispensable que exista un mecanismo que permita divulgar información en casos de un interés público apremiante. Las leyes de Canadá y México establecen requisitos de interés público, al igual que el Artículo 35 de la ley de Trinidad y Tobago:

A pesar de cualquier ley en contrario, las autoridades otorgarán acceso a un documento exento cuando exista evidencia razonable de que se haya producido o probablemente se produzca un/una importante:

(a) abuso de autoridad o incumplimiento de un deber oficial;

(b) injusticia contra una persona;

(c) peligro para la salud o seguridad de un individuo o el público; o bien,

(d) uso no autorizado de fondos públicos,

y si, dadas las circunstancias, el hecho de permitir el acceso al documento se justifica por el bien público considerando tanto el posible beneficio como el potencial daño que pudiera resultar de tal acción.

Si bien son más limitadas, las leyes de Ecuador y Perú también establecen que la información relacionada con investigaciones de violaciones de los derechos humanos no se puede ocultar en ningún caso. El Artículo 18 de la ley peruana señala que:

...no se considerará como información clasificada la relacionada a la violación de derechos humanos o de las Convenciones de Ginebra de 1949 realizada en cualquier circunstancia, por cualquier persona. Ninguna de las excepciones señaladas en este artículo puede ser utilizada en contra de lo establecido en la Constitución Política del Perú.

Dichas disposiciones son herramientas importantes para quienes trabajan en la defensa de los derechos humanos. En Perú, por ejemplo, dichos artículos contribuyeron a la revelación de información sobre las operaciones antiterroristas contra Sendero Luminoso en los años ochenta y noventa. Por ejemplo, en mayo de 2003 la ONG IPYS solicitó el expediente del caso de la matanza en el penal de Lurigancho del año 1986, un expediente que se inició en el año 1986 y concluyó en el año 1990. Previamente, la dificultad para acceder a tales expedientes se debió primero a que los casos fueron vistos en el fuero militar y segundo a la práctica en Perú (tanto en el fuero militar como civil) de que la publicidad de los procesos sólo abarca a las audiencias públicas y no a todo el proceso, reservándose la mayor parte de la información a las partes involucradas y sus abogados. Utilizando la nueva ley de transparencia, IPYS solicitó y recibió información que sirvió para conocer a los jefes del operativo militar que mataron a los presos, los nombres del las personas procesadas y la forma cómo cometieron el delito. 
3 Defensoría del Pueblo de Perú, Informe Defensorial № 97 A Dos Años de la Comisión de la Verdad y Reconciliación.

4 Ibíd, p. 316, Conclusión № 47.
Sin embargo, la Defensoría del Pueblo Peruano en su informe de septiembre 2005 "A Dos Años de la Comisión de la Verdad y Reconciliación" ${ }^{3}$ constató que existan todavía significativos problemas para recibir información relativa a los nombres del personal militar que prestó servicios en bases contraterroristas, y sobre la instalación y el tiempo de funcionamiento de dichos bases. El defensor criticó que no se observaban las normas vigentes en materia de conservación de archivos y documentos, tampoco las de transparencia y acceso a la información pública. Por ello, en algunos casos se ha brindado información y en otros se ha negado, mientras que en otros contestan "que se ha incinerado", según se señala en las respuestas de la Secretaría General del Ministerio de Defensa. En particular, el defensor opina que

"la información contenida en las Bases de Datos de las Direcciones de Personal de las Fuerzas Armadas, es información pública que no corresponde, en principio, a los supuestos de información secreta, reservada o confidencial, contemplados por la Ley de Transparencia y Acceso a la Información Pública (artículos 15\%, $16^{\circ}$ y 17\%). Por tanto, las instituciones armadas están obligadas a entregar esta información cuando sea solicitada. Por otra parte, debe tenerse en cuenta que el artículo $18^{\circ}$ de la misma norma prescribe que no se considerará como información clasificada. Sin embargo, aún cuando se demostrara que alguna de las personas cuyos datos se solicitan continúan ejerciendo actividades de seguridad nacional y que la revelación de dicha información pudiera poner en riesgo su vida o integridad, los/las jueces, en ejercicio de sus atribuciones jurisdiccionales, sí se encuentran facultados a conocer tales datos, de conformidad con el mismo artículo $18^{\circ}$, porque esa información es imprescindible para llegar a la verdad"4.

Además de lo relativo a la cuestión de la verdad histórica, está el derecho de saber vinculado con las elecciones. Respecto de la información sobre el candidato presidencial Ollanta Humala, un medio de comunicación solicitó al Ministerio de Defensa el expediente del señor Humala cuando estaba en Madre Mía (ciudad donde se han recibido denuncias de violación de derechos humanos contra el candidato). Una de las respuestas del Ministerio ha sido que la documentación correspondiente a esos años (1992) fue incinerada en cumplimiento de las normas que ellos poseen.

Por otra parte, en México, disposiciones similares se utilizaron para exigir la divulgación de los archivos de la Procuraduría contra el ex Presidente Echeverría por su participación en la masacre de estudiantes en Tlatelolco en 1968 que demostraron, inter alia, que algunos miembros del escuadrón paramilitar los "Halcones" habían manifestado ante los fiscales que habían recibido entrenamiento especial en Estados Unidos, Japón y Europa. Muchas leyes de acceso a la información son demasiado nuevas aún y todavía no son ampliamente utilizadas por las organizaciones de derechos humanos para exponer la verdad acerca de las violaciones a los derechos humanos del pasado, pero indudablemente tienen un fuerte potencial de ser utilizadas más frecuentemente en los procesos nacionales de verdad y reconciliación. 


\section{d) Solicitudes verbales}

Muchos solicitantes potenciales en las Américas son personas con baja escolaridad y escasa alfabetización. Para ellos, presentar una solicitud de información por escrito puede resultar oneroso, aun si el solicitante tiene un grado de instrucción suficiente como para poder leer la información que se le proporciona y utilizarla adecuadamente. Ya sea información sobre los pasos necesarios para el otorgamiento de un permiso de planos de construcción de una vivienda, hasta cómo solicitar asistencia social o cómo participar en programas de presupuestos participativos a nivel local, el requisito que les exige presentar la petición por escrito puede desincentivar la solicitud de información. Por otra parte, hacer la solicitud en forma verbal puede resultar fácil y eficiente, y estimular la participación ciudadana, especialmente tratándose del gobierno local.

Lamentablemente, la mayoría de las leyes de acceso a la información en las Américas exige la presentación de solicitudes por escrito. Solamente una de las 15 series de disposiciones legales examinadas (véase el Cuadro A al final de este artículo) mencionan específicamente la alternativa oral: la ley jamaiquina señala explícitamente la posibilidad de diferentes medios de acceso, que incluyen Ilamadas telefónicas, y responsabiliza a las autoridades de llevar el registro de las solicitudes. La ley peruana no establece que solamente se pueden presentar solicitudes por escrito, pero el reglamento de implementación de la ley (Decreto Supremo № 0722003-PCM de 7 de agosto de 2003) lo exige y proporciona orientación a los solicitantes en cuanto al uso de un formulario específico para la presentación de solicitudes. El formalismo burocrático típico de las administraciones públicas choca directamente en este punto con el espíritu de la ley y posiblemente con la esencia del derecho de obtener información. Si bien la limitación del alcance de un derecho mediante un reglamento sublegal constituye una violación a la ley peruana, hasta ahora la constitucionalidad del reglamento de acceso a la información no ha sido sujeto de una decisión judicial.

\section{e) Plazos y rechazos por silencio}

Los plazos para responder a las solicitudes establecidas por las leyes de las Américas generalmente cumplen con las normas internacionales, y van desde un corto intervalo de 7 días hábiles en Perú a 30 días calendario en Canadá y Jamaica. La autora ha estudiado más de 40 leyes y encontró que el promedio es de 14 días hábiles. Cabe destacar que el Instituto Federal de Acceso a la Información (IFAI) de México informa que, en promedio, las instituciones federales mexicanas responden las solicitudes en un plazo justo por debajo de los 11 días, aunque la ley otorga hasta 20 días, hecho que indica que los plazos cortos no implican un desafío significativo, si existe la voluntad política de divulgar la información.

Como se señala en la Sección 6 más adelante, un problema más difundido es que no se responde a todos los solicitantes, ya sea a tiempo o con retraso. Disposiciones legales que establezcan, sin lugar a duda, que los 
rechazos por silencio no son admisibles pueden servir para incentivar a los funcionarios públicos a divulgar la información. Disposiciones legales específicas que sirvan para disuadir la falta de acción administrativa, tales como las que existen en la ley panameña podrían servir para evitar este problema. Otras, como las leyes de Perú y la República Dominicana, definen el silencio de las autoridades como equivalente al rechazo, lo que da origen a la posibilidad de accionar ante tribunales inmediatamente. En México, la ley de transparencia interpreta directamente el silencio de las autoridades como una respuesta positiva, en el sentido de que la autoridad ha aceptado, en principio, divulgar la información. Los solicitantes que no reciben respuesta de la autoridad pertinente dentro de un plazo de 20 días hábiles pueden apelar directamente al IFAI, que es la institución mexicana encargada del seguimiento ante el organismo pertinente, para que entregue la información. En la práctica, esto significa que el organismo debe dar prioridad a las solicitudes no respondidas anteriormente y revelar información en todos los casos en que sea posible. Si la información corresponde a una o varias de las excepciones de la LFTAI en México, el organismo estatal debe informar de este hecho al solicitante inmediatamente, justificando los motivos por los cuales se aplica la excepción. Cada vez que el IFAI interviene por este motivo, el organismo pertinente debe asumir el costo de reproducción y entrega de la información, los cuales habitualmente son de cargo del solicitante, quedando los funcionarios públicos involucrados sujetos a posibles sanciones en virtud del derecho administrativo.

\section{El papel de las Comisiones de Información y las Defensorías del Pueblo}

Como se señaló anteriormente, la naturaleza del derecho a la información es tal que impone obligaciones positivas al Estado. En diciembre de 2004 el Relator Especial de Naciones Unidas para la Libertad de Expresión, el Representante de la Organización para la Seguridad y Cooperación en Europa sobre Libertad de los Medios de Comunicación y el Relator Especial de la Organización de Estados Americanos para la Libertad de Expresión, emitieron una declaración conjunta señalando que no sólo existe el derecho a la información, sino que "la autoridad pública que procure denegar el acceso debe demostrar que la información está amparada por el sistema de excepciones" y que debe existir la posibilidad de apelar cualquier denegación de solicitud de información ante un órgano independiente "con plenos poderes para investigar y solucionar dichos reclamos".

Los organismos independientes de fiscalización, generalmente conocidos como Comisiones de Información, desempeñan un papel fundamental en cuanto a educar a la sociedad y a los funcionarios públicos y en garantizar la eliminación de todos los obstáculos al libre flujo de la información. No todas las leyes de acceso a la información que en la actualidad existen en las Américas establecen órganos independientes dedicados especialmente a la supervisión y promoción de la ley, hecho que en algunos casos está ocasionando falta de conciencia acerca de 
este derecho entre el público e incluso en el gobierno mismo. Una excepción destacable es México, país donde la LFTAI de 2002 creó una comisión de información, a saber el IFAI. El presupuesto anual del IFAI que asciende a US\$22 millones (alrededor de 240 millones de pesos mexicanos) refleja el compromiso político asumido por el gobierno del Presidente Vicente Fox a favor de la promoción de la transparencia, es el mayor del mundo para una institución de esta naturaleza, incluye la apertura de millones de páginas de archivos históricos y es comparable con el equivalente de los aproximadamente US\$19 millones otorgados en el Reino Unido en el período 2003/4 para el Comisionado de Información (que también se encarga de la protección de la información).

Vale la pena analizar los logros del IFAI dado que ofrece modelos importantes en cuanto a las medidas que debieran tomar los gobiernos para garantizar el cumplimiento eficaz del derecho a la información. Una de las innovaciones introducidas por el IFAI ha sido su trabajo destinado a reducir los obstáculos burocráticos que limitan el ejercicio del derecho a solicitar información. Para quienes tienen acceso a Internet, existe un portal de ventana única denominado SISI (Sistema Integrado de Solicitudes de Información) que recibe las solicitudes y entrega un número de referencia para seguir la pista a la situación de la solicitud. Los solicitantes de Ciudad de México que carezcan de acceso a Internet pueden acercarse a una de las oficinas de IFAI y presentar la solicitud en los computadores disponibles para este fin. Para quienes carecen de acceso a Internet y necesitan seguir la pista de su solicitud o deseen orientación sobre cómo presentar una solicitud, el teléfono de IFAI atiende de 09:00 a 19:00 horas los días hábiles. El IFAI maneja las apelaciones de las solicitudes y ha acelerado los sistemas para abordar problemas tales como el silencio de las autoridades. En consecuencia, las estadísticas del año 2005 muestran que, de las 77.930 solicitudes presentadas a las autoridades federales en los primeros dos años luego de la entrada en vigencia de la ley (11 de junio de 2003), un total de $89,4 \%$ recibieron respuesta. De las 815 apelaciones presentadas al IFAI sobre el fondo del asunto durante este período, el $78,4 \%$ se resolvió en forma parcial o total a favor de los solicitantes.

El IFAI ha realizado importantes inversiones en la concientización sobre este derecho: tiene un programa de radio semanal sobre temas de transparencia, que se transmite por frecuencia AM e Internet, y se dice que ha gastado unos US\$6 millones en publicidad; las encuestas de opinión muestran que la conciencia sobre la ley de acceso a la información ha llegado a niveles muy elevados, con un $60 \%$.

El considerable éxito del IFAI lo convierte en un modelo importante para América Latina, pero los costos involucrados hacen poco probable que este organismo se replique de igual modo en otros países. Otros modelos de fiscalización, de corte más modesto aunque igualmente eficaces, incluyen los Comisionados de Información de las provincias canadienses y algunos estados de Estados Unidos, las Comisiones de medio tiempo que existen en Francia y Portugal y los Comisionados de Información 
individuales que hay en países más pequeños que son los integrantes más recientes del Club de Estados Democráticos, tales como Hungría, Serbia y Eslovenia. Por ejemplo, el presupuesto para 2006 de la Comisionado de Información de Eslovenia es $€ 854.000$ (US \$1.067.500).

Otra institución que está desempeñando un papel importante en algunos países en la promoción y defensa del derecho de acceso a la información es la Defensoría del Pueblo. En Perú, el funcionario de la Defensoría del Pueblo ha tenido un papel activo en la capacitación de funcionarios públicos y jueces en lo que se refiere al cumplimiento de la ley de 2002 sobre el acceso a la información; en Panamá, la Defensoría del Pueblo ha asumido más de 35 casos de habeas data para reforzar el derecho a la información, los que incluyen 6 en contra de instituciones de gobierno para obligarlos a publicar información institucional esencial en el Portal de Transparencia establecido por la Defensoría, el cual contiene información sobre 66 instituciones públicas y los sueldos de más 170.000 funcionarios públicos, lo que representa US\$114 millones en sueldos mensuales.

Las leyes de Ecuador, Bélice y Trinidad y Tobago también asignan responsabilidades correspondientes a la fiscalización de la ley al Defensor (Ombudsman) mientras que la ley canadiense establece un Comisionado de Información.

\section{El acceso a la información como herramienta contra la corrupción y la mala administración}

La importancia de la transparencia en la lucha contra la corrupción y el mal gobierno es ampliamente reconocida en las Américas y forma parte del impulso que ha llevado a la adopción de muchas de las nuevas leyes. Las leyes de acceso a la información se han concebido como mecanismos para promover la participación en la toma de decisiones con el fin de incrementar la calidad de la gestión pública gubernamental en la región.

La Convención Interamericana contra la Corrupción no menciona específicamente el derecho a la información aunque en el Artículo III sobre Medidas Preventivas hace referencia a "Mecanismos para estimular la participación de la sociedad civil y de las organizaciones no gubernamentales en los esfuerzos destinados a prevenir la corrupción". El grupo de expertos encargado de supervisar la implementación de este tratado, el Mecanismo de Seguimiento de la Implementación de la Convención Interamericana contra la Corrupción incluye, no obstante, en sus informes de país, una sección sobre "mecanismos para el acceso a la información" en la cual se analizan las disposiciones sobre transparencia de cada país.

En consecuencia, los expertos han planteado inquietudes cuando un país carece de leyes de pleno acceso a la información, como en el caso de Argentina, en el que se tomó nota del proyecto de ley y se señaló: "No obstante, el Comité considera oportuno instar a la República Argentina a que continúe avanzando en la adopción de un régimen general en materia 
de acceso a la información". Igualmente, los expertos destacaron la necesidad de mejorar el mecanismo de acceso en Chile al manifestar que: "El comité estima que sería útil que la República de Chile considerara complementar y fortalecer dichas normas [ley de probidad] de tal manera que el derecho de acceso a la información abarcara áreas como la de las políticas públicas, y que las garantías previstas para su ejercicio se vieran fortalecidas" ${ }^{\prime 5}$.

En la práctica aumentan los ejemplos en la región sobre la utilización de leyes de acceso a la información en el trabajo para promover el buen gobierno y luchar contra la corrupción. El seguimiento del gasto público en México por parte del grupo Fundar ha significado el empleo activo del derecho a la información en virtud de la ley de 2002 promulgada por México sobre el acceso a la información junto con reunir a una serie de fuentes diversas de información, incluyendo la que se publica en sitios web del gobierno y de instituciones que reciben financiamiento, tales como los hospitales. Por ejemplo, Fundar realizó un seguimiento de 600 millones (aproximadamente US\$60 millones) de fondos federales para el tratamiento de VIH/SIDA y descubrió que algunos de los hospitales que tenían un gran número de pacientes con esta enfermedad recibían menos recursos que los que tenían menos pacientes, mientras que otros hospitales simplemente no recibían fondos, a pesar de que trataban a dichos enfermos. El resultado fue una reasignación de recursos por parte de la Secretaría de Salud.

Como resultado de solicitudes de información presentadas para hacer un seguimiento al desembolso de los fondos, Fundar descubrió también que 30 millones (aproximadamente US\$3 millones) destinados a la promoción de la salud de la mujer y prevención del VIH/SIDA habían sido asignados a la organización Pro-Vida. Además de la evidencia de nepotismo y corrupción en la asignación y utilización de los recursos, se descubrió que más de un $80 \%$ de los fondos habían sido usados por ProVida para contratar a empresas de relaciones públicas con el fin de realizar campañas en contra de la entrega de anticonceptivos a las mujeres. A raíz del escándalo resultante, la Secretaría de Salud solicitó el reembolso de los recursos mientras que la Secretaría de la Función Pública inició las investigaciones criminales del caso.

Las solicitudes de acceso a la información también han ayudado a garantizar precios justos en los servicios públicos. En Panamá, por ejemplo, la ley que regula las empresas de energía privatizadas solamente permite aumentar las tarifas en caso de que se registren pérdidas. Cuando una compañía de electricidad intentó aumentar sus tarifas en un 30\%, el Ombudsman presentó una solicitud pidiendo los estados financieros que justificaban esa necesidad. Luego de una presentación ante los tribunales por el Ombudsman, para obligar a la empresa a entregar los documentos, quedó demostrado que esta efectivamente tenía ganancias y que carecía de la justificación necesaria para aumentar las tarifas, con lo que se puso fin al alza propuesta.
5 Ver página del Mecanismo de Seguimiento de la Implementación de la Convención Interamericana contra la Corrupción http:// www.oas.org/juridico/ spanish/ mec_ron1_inf.htm donde se presentan los informes adoptados por el Comité de Expertos sobre las disposiciones seleccionadas para ser analizadas en el marco de la Primera Ronda. 


\section{Respeto al derecho a la información en la práctica}

Para garantizar que el público pueda ejercer el derecho a la información, cada gobierno tiene la clara responsabilidad de implementar una serie de medidas tales como nombrar funcionarios públicos para que se ocupen de las solicitudes de información, además de generar procesos internos que permitan que las solicitudes de información sean atendidas dentro de los plazos que señala la ley. Por ejemplo, conforme a la ley de la República Dominicana promulgada en el año 2004, cada institución señalada por dicha ley debe nombrar un funcionario de información ("responsable de acceso a la información"), además de establecer "oficinas de acceso a la información" en cada organismo público. Sin embargo, en enero de 2006, solamente el $24 \%$ de los organismos públicos contaba con funcionarios de información y en tan sólo el $4 \%$ de las instituciones se había creado el puesto de encargado de acceso a la información. La encuesta, realizada por Participación Ciudadana, descubrió también que, en los casos en que se había nombrado a tales funcionarios, no se había cumplido con el procedimiento de concurso abierto exigido por la ley.

La falta de cumplimiento en cuanto a asegurar que existan los sistemas internos adecuados puede conducir a graves infracciones al derecho a la información. En un estudio de monitoreo de cuatro países latinoamericanos (Argentina, Chile, México y Perú) realizado en el año 2004 por la Open Society Justice Initiative, el grado de silencio de las autoridades iba desde un nivel aceptable del $21 \%$ en México a un impactante $69 \%$ en Chile. Una investigación más profunda en dichos países demostró que había una serie de razones que daban cuenta del silencio de las autoridades y que la más frecuente era la incapacidad de los sistemas internos de manejo de la información más que la falta de voluntad política en sí. Independientemente de las razones, la absoluta falta de respuesta frente a una solicitud de información presentada por el público a un organismo estatal constituye una clara violación del derecho a la información. Efectivamente, el caso de Claude Reyes et al. vs. Chile, que se debatió ante la Corte Interamericana de Derechos Humanos el 3 de abril de 2006, se originó en un rechazo por silencio de la solicitud presentada por la Fundación Terram (con base en Santiago) pidiendo al Comité de Inversiones Extranjeras (CIF) que le entregara copia de un informe con datos recopilados por el CIF sobre los antecedentes generales de una empresa extranjera involucrada en el Proyecto Río Cóndor, un proyecto maderero controversial. El Comité no respondió la solicitud y las apelaciones de los solicitantes ante los tribunales chilenos fueron desestimadas en forma sumaria.

Otro problema grave es la discriminación en la entrega de información. El estudio de monitoreo de Justice Initiative mencionado anteriormente determinó que, en general, es más fácil para representantes del mundo del periodismo y de la sociedad civil obtener información que para los ciudadanos comunes y corrientes, y que hay una discriminación significativa en contra de quienes pertenecen a sectores excluidos, ya 
sean grupos étnicos o socioeconómicos (véase el Cuadro B al final de este artículo). Esta conclusión respalda la experiencia anecdótica de los grupos de la sociedad civil de la región, los cuales informan que, cuando los solicitantes vienen a quejarse acerca de denegaciones de información, las ONGs a menudo pueden resolver el problema simplemente volviendo a presentar la solicitud.

La discriminación de cualquier tipo por parte de instituciones de gobierno constituye una violación particularmente grave de los derechos humanos. Está prohibida por las convenciones internacionales y las leyes nacionales, incluidas algunas leyes de acceso a la información, tales como la ley peruana cuyo Artículo 13 establece que:

"La entidad de la Administración Pública a la cual se solicite información no podrá negar la misma basando su decisión en la identidad del solicitante".

La discriminación en la entrega de la información exacerba la brecha entre los "ricos en información" y los "pobres en información" ya generada por el acceso diferencial a las tecnologías de la información y la comunicación. Para que el derecho de acceso a la información redunde en beneficio de la protección de otros derechos y para facilitar el verdadero desarrollo económico y social, la información tiene que estar disponible para todos y no solamente para los miembros de la élite y los integrantes de los grupos en el poder. Un desafío apremiante en el campo de los derechos humanos para los gobiernos y las asociaciones de la sociedad civil en las Américas es lograr la igualdad de acceso a la información pública e identificar y erradicar la discriminación en la entrega de la información.

\section{Desafíos para el futuro}

Año con año, se logran avances significativos en el campo del respeto por el derecho a la información en las Américas. El año 2006 ofrece la perspectiva de la promulgación de nuevas leyes, con proyectos de ley que se están discutiendo en una serie de países entre los que se cuentan las Islas Caimán, El Salvador, Guatemala, Paraguay y Uruguay, además de la posible resucitación del proyecto de ley de Argentina. Seguramente se contará con mayor jurisprudencia en el tema y ciertamente parte de ella será de la Corte Interamericana de Derechos Humanos.

Quedan retos significativos, sin embargo. No sólo es necesario cambiar la cultura de manejar la administración de la región en forma secreta, sino que también el marco jurídico que obstaculiza la transparencia. El siguiente desafío que deberán acometer los legisladores, los tribunales y la sociedad civil es armonizar la gran variedad de leyes, decretos y reglamentos que establecen el secreto, cambiándolos por nuevas leyes de acceso a la información para así garantizar que la información necesaria para la defensa de todos los derechos humanos ingrese al dominio público. 


\begin{tabular}{|c|c|c|c|c|c|c|c|c|c|c|c|c|c|c|c|}
\hline |eadde ןe!’!pn| & $>$ & & \rangle & $>$ & $>$ & $>$ & $>$ & $>$ & $>$ & $>$ & $>$ & $>$ & $>$ & $>$ & $>$ \\
\hline 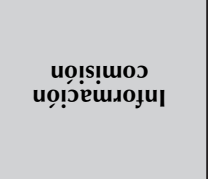 & $\begin{array}{l}\frac{0}{0} \\
\frac{\pi}{0} \\
\frac{0}{0.0} \\
\frac{0}{E} \\
0\end{array}$ & & 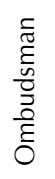 & & $\begin{array}{l}\frac{0}{0} \\
\frac{\pi}{0} \\
\frac{0}{0} \\
\frac{.0}{\varepsilon} \\
0\end{array}$ & & & & 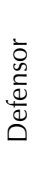 & & $\begin{array}{l}\frac{0}{0} \\
\frac{\pi}{0} \\
\frac{0}{0.0} \\
\frac{0}{\varepsilon} \\
0\end{array}$ & & & & 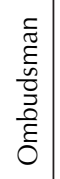 \\
\hline 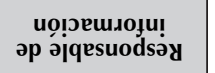 & $>$ & & & $>$ & $>$ & & & $>$ & & $>$ & $>$ & & $>$ & $>$ & $>$ \\
\hline $\begin{array}{c}\text { ex!joroud } \\
\text { uọjeว!|qnd }\end{array}$ & $>$ & & $>$ & $>$ & $>$ & & $>$ & $>$ & $>$ & $>$ & $>$ & & $>$ & $>$ & $>$ \\
\hline 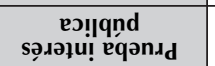 & $>$ & & $>$ & & $>$ & & & & $>$ & & $>$ & & $>$ & & $>$ \\
\hline $\begin{array}{l}\text { sep!uyəp } \\
\text { səuọdəoว }\end{array}$ & $>$ & $>$ & $>$ & & $>$ & & & $>$ & $>$ & $>$ & $>$ & $>$ & $>$ & $>$ & $>$ \\
\hline 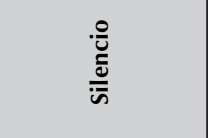 & & 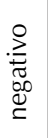 & & & & 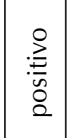 & 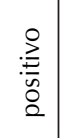 & 竞 & 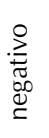 & & 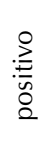 & $\begin{array}{l}\frac{0}{0} \\
\frac{0}{2} \\
\frac{0}{2} \\
\frac{0}{2}\end{array}$ & 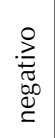 & $\begin{array}{l}\stackrel{0}{D} \\
\stackrel{D}{\infty} \\
\stackrel{\infty}{\complement} \\
\stackrel{0}{\complement}\end{array}$ & \\
\hline 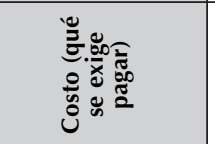 & 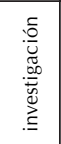 & $\frac{\pi}{\frac{\pi}{\partial}}$ & 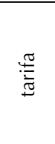 & $\frac{\pi}{\frac{\pi}{0}}$ & 葶 & $*$ & $\frac{\mathscr{\pi}}{\frac{\pi}{0}}$ & 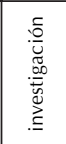 & $\frac{\mathscr{\pi}}{\overline{0}}$ & $\frac{\pi}{\frac{\pi}{0}}$ & $\frac{\pi}{\frac{\pi}{0}}$ & $\frac{\tilde{\pi}}{\frac{\pi}{0}}$ & $\frac{\pi}{\frac{\pi}{0}}$ & $\frac{\mathscr{m}}{\frac{\pi}{0}}$ & 䒕 \\
\hline$\stackrel{\pi}{0}$ & 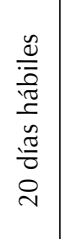 & $\begin{array}{l}\frac{\mathscr{d}}{\overline{0}} \\
\frac{\pi}{\tilde{J}} \\
\frac{\pi}{0} \\
0 \\
0\end{array}$ & 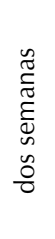 & 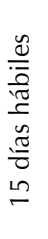 & $\begin{array}{l}\frac{0}{\frac{0}{\pi}} \\
\frac{\pi}{0} \\
\frac{0}{\pi} \\
\frac{0}{\pi} \\
\frac{\pi}{0} \\
\frac{\pi}{0} \\
0\end{array}$ & 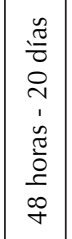 & 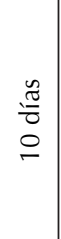 & 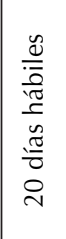 & $\begin{array}{l}\underset{\mathscr{I}}{0} \\
0 \\
0\end{array}$ & 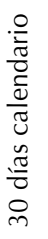 & 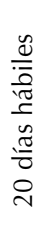 & 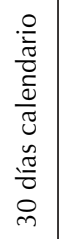 & $\begin{array}{l}\frac{\mathscr{\theta}}{\overline{0}} \\
\frac{\pi}{\pi} \\
\frac{\pi}{0} \\
n\end{array}$ & 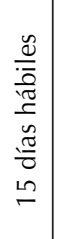 & $\begin{array}{l}\frac{0}{0} \\
\frac{\pi}{0} \\
\frac{0}{0} \\
\frac{0}{0} \\
\frac{n}{0} \\
\frac{\pi}{0} \\
0 \\
\end{array}$ \\
\hline 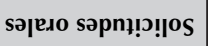 & & & & $>$ & & & & & & $>$ & & & & & \\
\hline 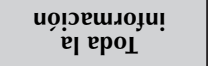 & $>$ & $>$ & $>$ & $>$ & $>$ & & $>$ & $>$ & $>$ & $>$ & $>$ & $>$ & $>$ & $>$ & $>$ \\
\hline 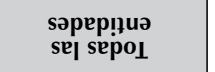 & $>$ & $>$ & & $>$ & $>$ & & $>$ & & $>$ & & $>$ & $>$ & $>$ & $>$ & \\
\hline 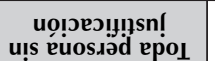 & $>$ & $>$ & $>$ & $>$ & & $>$ & $>$ & $>$ & $>$ & $>$ & $>$ & $>$ & $>$ & & $>$ \\
\hline 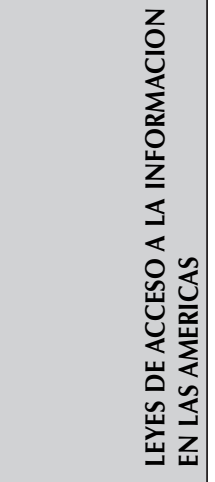 & 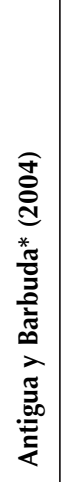 & 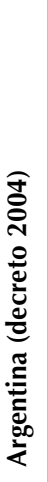 & 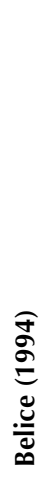 & 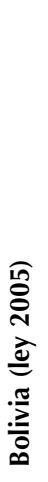 & 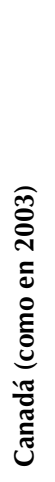 & 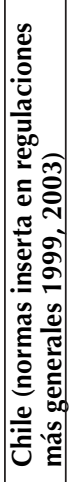 & 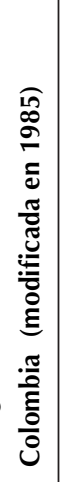 & 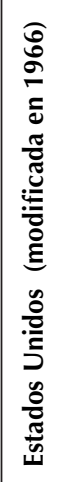 & 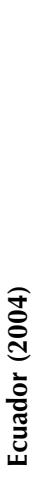 & 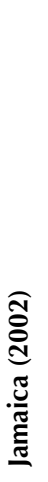 & 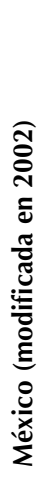 & 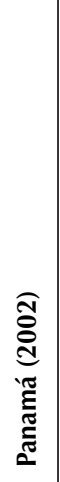 & 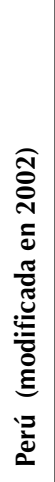 & 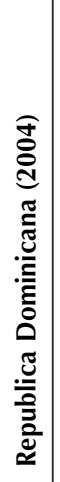 & 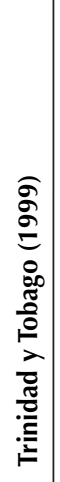 \\
\hline
\end{tabular}




\section{CUADRO B}

De acuerdo con un estudio de monitoreo de acceso a la información en 14 países realizado por el Open Society Justice Initiative, miembros de grupos excluidos recibieron significativamente menos información que otros solicitantes. Los datos del siguiente cuadro muestran los resultados para América Latina (Fuente: Transparency and Silence, Open Society Justice Initaitive, 2006 www.justiceinitiative.org)

\begin{tabular}{|c|c|c|c|c|}
\hline País & $\begin{array}{l}\text { Grupo solicitante } \\
\text { excluido }\end{array}$ & $\begin{array}{l}\text { Promedio de } \\
\text { información } \\
\text { recibida en } \\
\text { el país }\end{array}$ & $\begin{array}{l}\text { Mayor } \\
\text { información } \\
\text { recibida / } \\
\text { solicitante }\end{array}$ & $\begin{array}{l}\text { Solicitante } \\
\text { de grupo } \\
\text { excluido: } \\
\text { información } \\
\text { recibida }\end{array}$ \\
\hline Argentina & $\begin{array}{l}\text { Mujer de bajos ingresos, de la } \\
\text { provincia interior de Mendoza (las } \\
\text { características son clase social, } \\
\text { género y el hecho de no ser de la } \\
\text { capital). }\end{array}$ & $17 \%$ & $\begin{array}{c}\mathbf{3 0} \% \\
\text { (periodista de } \\
\text { oposición) }\end{array}$ & $0 \%$ \\
\hline Chile & $\begin{array}{l}\text { Miembro de comunidad indígena } \\
\text { mapuche, residente en Santiago } \\
\text { que está comprometido con la } \\
\text { comunidad mapuche residente ahí. }\end{array}$ & $17 \%$ & $\begin{array}{l}\mathbf{3 5 \%} \\
\text { (persona no } \\
\text { afiliada) }\end{array}$ & $10 \%+$ \\
\hline México & $\begin{array}{l}\text { Hombre indígena soltero, de } 33 \text { años } \\
\text { de edad, que nació en Tlalchichilco, } \\
\text { Veracruz, México. }\end{array}$ & $25 \%$ & $\begin{array}{l}\quad \mathbf{4 7 \%} \\
\text { (persona no } \\
\text { afiliada) }\end{array}$ & $11 \%$ \\
\hline Perú & $\begin{array}{l}\text { Hombre de raza negra, de } 43 \text { años } \\
\text { de edad, educación limitada, trabaja } \\
\text { como chofer. }\end{array}$ & $23 \%$ & $\begin{array}{c}\mathbf{4 5} \% \\
\text { (periodista } \\
\text { progobierno) }\end{array}$ & $4 \%$ \\
\hline
\end{tabular}

+ En cada país, el grupo solicitante excluido recibió la menor cantidad de información, excepto en Chile, donde ocupó el segundo lugar; una ONG solicitante chilena recibió $0 \%$ de información. 
